\title{
Role of plants in anticancer drug discovery
}

\author{
Jabeena Khazir ${ }^{a}$, Bilal Ahmad Mir ${ }^{\text {b* }}$, Lynne Pilcher ${ }^{a}$, Darren L Riley ${ }^{a}$ \\ ${ }^{a}$ Department of Chemistry, University of Pretoria, Pretoria 0028, South Africa \\ ${ }^{\mathrm{b}}$ Centre for Microbial Ecology and Genomics, Department of Genetics, University of \\ Pretoria, Pretoria 0028, South Africa
}

\section{Highlights}

- Cancer is second deadly disease after cardiovascular diseases.

- There is a tremendous need to discover novel safer and more effective anticancer agents.

- Plants serve as a basis for promising therapeutic agents for cancer treatment.

- Important plant derived anticancer agents have been discussed here.

- Some potential plant derived lead molecules have also been discussed.

\section{*Corresponding author:}

Centre for Microbial Ecology and Genomics,

Department of Genetics, University of Pretoria,

Pretoria 0028, South Africa

Cell number: +27745355286

E-mail: bilal.mir@up.ac.za 


\begin{abstract}
Cancer is one of the major causes of death and the number of new cases, as well as the number of individuals living with cancer, is expanding continuously. Worldwide the alarming rise in mortality rate due to cancer has fuelled the pursuit for effective anticancer agents to combat this disease. Finding novel and efficient compounds of natural origin has been a major point of concern for research in the pharmaceutical sciences. Plants have been seen to possess the potential to be excellent lead structures and to serve as a basis of promising therapeutic agents for cancer treatment. Many successful anti-cancer drugs currently in use or their analogues are plant derived and many more are under clinical trials. This review aims to highlight the invaluable role that plants have played, and continue to play, in the discovery of anticancer agents.
\end{abstract}

\title{
Graphical abstract
}

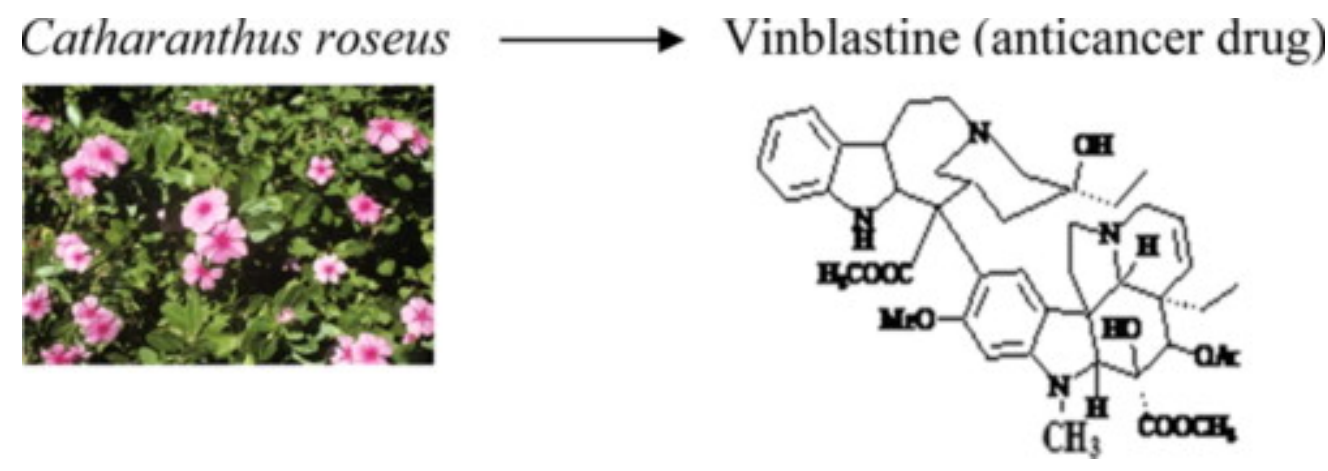

Keywords cancer, drugs, natural products, plant derived anticancer drugs. 


\section{Introduction}

Cancer is a multifaceted disease that represents one of the leading causes of mortality in developed countries. Worldwide, one in eight deaths is due to cancer and it is the second most common cause of death in the US, exceeded only by heart disease, accounting for nearly one of every four deaths (http://www.cancer.org). The World Health Organization (WHO) projects that without immediate action, the global number of deaths from cancer will increase by nearly $80 \%$ by 2030 , with most occurring in low- and middle-income countries. External factors (such as tobacco, infectious organisms, chemicals, and radiation) and internal factors (inherited mutations, hormones, immune conditions, and mutations that occur from metabolism) are mostly responsible for cancer. These causal factors may act together or in sequence to initiate or promote the development of cancer (http://www.state.nj.us /health/cancer/causes.shtml).

While tremendous efforts have been made over the past decades to improve the available therapeutic options, and a large number of potent chemotherapeutic anticancer agents have been identified and successfully used in clinical practice, cancer still remains a major cause of disease and death in most countries. New therapeutic options to treat cancer are a high priority for most of the pharmaceutical companies and independent research organisations worldwide. Considerable research activity is devoted to the discovery of more potent treatments, while minimising their toxic side effects. However, most anticancer agents display a narrow therapeutic window due to their lack of selectivity against cancer cells (Shengquan et al., 2013; Kratz et al., 2008). The ultimate goal of cancer chemotherapy is the development of selective drugs that can kill malignant tumor cells or render them benign without affecting normal cells. Thus, there is an overwhelming need to develop new chemopreventative agents that are both effective and safe (Sporn and Liby, 2005). One practical approach to this problem is the use of terrestrial plants as a platform for drug development.

Plants have played a dominant role in the development of sophisticated traditional medicine systems. The WHO estimates that approximately $80 \%$ of the population in some Asian and African countries depend on traditional medicine for primary health care. Plant products, however, also play an important secondary role in the health care sectors of developed countries, with $70 \%$ to $80 \%$ of populations of developed countries having used some form of alternative or complementary medicine (e.g. acupuncture). Herbal treatments are the most popular form of traditional medicine, and are highly lucrative in the international marketplace. The global market for herbal products is expected to reach \$5 Trillion by 2050 (Anand and Neetu, 2011). 
Plants products have a long history of use in the treatment of cancer. Hartwell in his review of plants used against cancer lists more than 3000 plant species (Kaur et al., 2011). Plant based drug discovery has resulted in the development of many anticancer drugs currently in clinical use. Besides this it also provides a platform for design of novel and safe drugs through proper understanding of the complex synergistic interaction of various constituents of anticancer herbs (Larkin, 1983; Saxe, 1987)

There are four major structural classifications of plant-derived anticancerous compounds, namely vinca alkaloids, epipodophyllotoxin lignans, taxane diterpenoids and camptothecin quinoline alkaloid derivatives. These substances embrace some of the most exciting new chemotherapeutic agents currently available for use in a clinical setting.

\section{Vinca alkaloids and its semisynthetic analogues}

The era of using plant material as anticancer agents started with the isolation of two alkaloids vinblastine (1) and vincristine (2) from the Madagascar periwinkle, Catharanthus roseus G. Don (Apocynaceae) (Verma and Singh, 2010). These two drugs have been used in clinical oncology for almost 50 years and work by blocking the polymerization of tubulin molecules into microtubules, preventing the formation of the mitotic spindle which result in metaphase arrest and apoptosis (Jordan et al, 1991). A series of semisynthetic analogues of these two important drug molecules have been developed. The first semisynthetic vinca alkaloid to enter into human clinical trials was vindesine (eldisine, 3 ) in which the $\mathrm{C}(23)$ acetyl group in vinblastine was changed to an amido group (Jordan and Wilson, 2004). Vindesine is primarily used to treat acute lymphocytic leukemia (ALL). Less frequently, it is prescribed for use in breast cancer, blast crisis of chronic myelocytic leukemia (CML), colorectal cancer, non-small cell lung cancer (NSCLC), and renal cell cancer (kidney cancer). Vindesine is used in countries such as Britain, South Africa, and several European countries, but it is not approved by the FDA, and is thus not commercially available in the U.S. Eli Lilly discontinued Eldisine in Canada in 1998 to make way for newer, more effective vinca alkaloid drugs (http://www.encyclopedia.com/topic/Vindesine.aspx).

Vinorelbine (Navelbine, 4), is another semisynthetic derivative of vinblastine in which the bridge linking the indole ring to the piperidine nitrogen has been shortened by one carbon and water has been eliminated from the piperidine ring. The drug was approved in France in 1989 under the brand name Navelbine for the treatment of NSCLC (http://www.pierrefabre.com/en). It gained approval to treat metastatic breast cancer (MBC) in 1991. Vinorelbine received approval by the FDA in December 1994 sponsored by Burroughs 
Wellcome Company. Pierre Fabre Group now markets Navelbine in the U.S (Smith, 1995; http://www.drugs.com/pro/vinorelbine.html).

Vinflunine (5), a dihydro-fluoro derivative of vinorelbine was approved by the European medical agency (EMEA) in 2009 as second line chemotherapy in metastatic urothelial cancer (Bachner and De Santis, 2008; Mamtani and Vaughn, 2011).

Similar to other members in the vinca alkaloid class, vinflunine binds to the tubulin molecules, inhibiting microtubule polymerization and the formation of tubulin paracrystals (Bennouna et al., 2008; Kruczynski et al., 1998; Pourroy et al., 2004; Simoens et al., 2006). This interaction then leads to $\mathrm{G}_{2} / \mathrm{M}$ phase arrest and apoptosis results (Lobert and Puozzo, 2008; Kruczynski et al., 2002). It has broad in vitro and in vivo activities against many different malignant cell lines Vinflunine is actively being studied in patients with advanced stage diseases especially MBC, and NSCLC in phase II/III clinical trials. More phase I/II trials are also being organized to evaluate its efficacy in other advanced solid tumours (Ng, 2011).

In August 2012, the FDA approved vincristine sulphate liposome injection (Marqibo, Talon Therapeutics, Inc.) for the treatment of adult patients with Philadelphia chromosome-negative (Ph-) (ALL) in second or greater relapse or whose disease had progressed following two or more anti-leukaemia therapies. It is a new, targeted, nanoparticle-encapsulated, cancer therapeutic agent specifically designed to improve patient outcomes by combining the potential for enhanced efficacy with the potential for reduced toxicity. (http://www.marqibo.com).

Besides these approved vinca alkaloid drugs, many other derivatives are undergoing clinical trials including anhydrovinblastine (Hydravin, 6) which differs from vinblastine in having a 3'4' double bond in the catharanthine moiety a property it shares with vinorelbine (Navelbine) It entered the clinical trials in 1999 for the treatment of metastatic sarcoma of the lungs. As of 2003 it has been undergoing phase I trials to determine its maximum tolerated dose (MTD), dose-limiting toxicities (DLT) and pharmacokinetics given as a 1-h intravenous infusion once every 3 weeks in patients with advanced refractory solid tumours. The recommended phase II dose was found as $21 \mathrm{mg} / \mathrm{ml}$ (Ramnath et al., 2003), but Keryx discontinued its further development in 2005, but trials may still be ongoing by Prescient Neuropharma (Butler, 2008). The clinical trial website (www.clinicaltrials.gov) shows phase I (NCT00003882) trials for the treatment of advanced recurrent solid tumours. In addition to this, chemists have also grafted amino acid derivatives onto vinblastine, so as to facilitate transport of these large molecules into cell membranes. This work led to the synthesis of molecules with interesting 
pharmacological properties, namely vinglycinate (7) and vintripol (8), that are structural analogues of vindesine. Vinglycinate substituted by glycinate residue at the vindoline C-4 position entered phase I clinical trials in 1967, but concluded with toxicity (Armstrong et al., 1967; Budman, 1992). Although many other semi synthetic compounds have been developed from vinblastine and vincristine, none of these have exerted marked benefits in clinical evaluation.

\section{Taxol and its semisynthetic analogues}

The discovery of paclitaxel (Taxol, 9) from the bark of the Pacific Yew, Taxus brevifolia Nutt (Taxaceae) provides further evidence for the success of natural product drug discovery. No naturally occurring anticancer agent has made a bigger impact on cancer treatment than paclitaxel. Paclitaxel was the first compound discovered to promote microtubule formation and has been used in the treatment of several types of cancers particularly ovarian and breast cancers as well as NSCLC (Kinghorn and Seo, 1996). A number of its semisynthetic derivatives have been developed. The first to reach clinical use was docetaxel (10) which have shown significant clinical activity in a wide range of tumors and a different toxicity pattern than the parent compound (http://www.drugbank.ca/drugs/DB01248; Bissery et al., 1995; Gelmon, 1994) . However, both of the approved taxanes carry certain limitations, which scientists are still trying to overcome through synthesis of modified analogues. Modifications in the structures of these compounds have been made in an effort to discover novel agents with improved cytotoxicity in resistant tumours, decreased toxicity, and improved solubility. Also the lack of brain penetration of paclitaxel precluded further investigations of this compound in mouse models. The limited ability of paclitaxel and docetaxel to diffuse across the blood brain barrier (BBB) is believed to be caused at least in part by the P-glycoprotein (PGP) efflux pump (Kemper et al., 2003; Fellner et al., 2003) which is highly expressed in the BBB (Beaulieu et al., 1997). Thus, taxane analogues capable of overcoming PGP-mediated transport may result in improved brain penetration.

Cabazitaxel (11), an FDA approved semi-synthetic taxane was launched in 2010 for use in combination with prednisone for the treatment of prostate and hormone refractory prostate cancers (http://www.drugbank.ca/drugs/DB06772; Channing et al., 2011) . Cabazitaxel binds to and stabilizes tubulin, resulting in the inhibition of microtubule depolymerization and cell division, cell cycle arrest in the $\mathrm{G}_{2} / \mathrm{M}$ phase, and the inhibition of tumor cell proliferation (Channing et al., 2011). Unlike other taxane compounds, this agent is a poor substrate for the membrane-associated, multidrug resistance (PGP) efflux pump and may be useful for treating 
MDR tumours. In addition, cabazitaxel penetrates the BBB (http://www.medkoo.com/Anticancer-trials/Cabazitaxel.htm) and in combination with prednisone significantly extends overall survival in men with hormone-refractory prostate cancer previously treated with a docetaxel-containing regimen and also improves disease control (http://www.medicalnewstoday.com/articles/220304.php).

The approval of nanoparticle based formulation abraxane shows that improved formulation can have a dramatic effect (http://www.drugbank.ca/drugs/DB01229). Abraxane (ABI-007) is albumin-bound, 130-nm particle formulation of paclitaxel, free from any kind of solvent. It was first approved in the US in 2005 for its use as a breast cancer treatment. In 2012 it was approved for first-line treatment of metastatic NSCLC among patients who could not receive radiation therapy or curative therapy. Abraxane is a first in its class of drugs using nanoparticle albumin-bound (NAB) technology, acting as a mitotic inhibitor. Abraxane made sales of close to \$386 million in 2011 for its use as breast cancer treatment and was marketed by Celgene (http://www.medicalnewstoday.com/articles/255388.php).

Novel taxanes in development are being designed to improve the pharmacology and therapeutic index, and replace paclitaxel and docetaxel as standard treatments in NSCLC (Bao and Pokman, 2011). Several semi-synthetic agents have completed phase I/II clinical trials and are in phase III testing like paclitaxel poliglumex (CT-2103; Xyotax 12), which is an innovative macromolecular taxane designed to increase the therapeutic index of paclitaxel (Singer et al., 2005). It was reported to be undergoing phase III clinical trials for the treatment of NSCLC, and is positioned to be the first of its class to reach the market (Stewart et al., 2006; Haag and Kratz, 2006). It is also undergoing phase III trial in combination with carboplatin in the treatment of performance status (PS 2) patients with chemotherapy-naïve advanced NSCLC. When compared to paclitaxel/carboplatin combination, paclitaxel poliglumex (PPX) and carboplatin failed to provide superior survival in the first-line treatment of PS 2 patients with NSCLC, but the results with respect to progression-free survival and overall survival were comparable and the PPX regimen was more convenient (Langer et al., 2008). In the clinical trials database, four phase II trials are shown. Two involve the treatment of patients with recurrent or persistent ovarian epithelial cancer or peritoneal cancer (NCT00045682) and fallopian tube cancer (NCT00017017). The other two are in the treatment of MBC (NCT00148707) and in ovarian cancer (NCT0006990).

Other taxol analogues like 7-DHA-Taxol (Taxaprexin 13, Lutipold pharmaceuticals) made by linking paclitaxel to docosahexaenoic acid (DHA), a fatty acid that is easily taken up by tumor cells. As of 2006 it has been undergoing open-label, non-randomized, multi- 
institutional phase II trials to assess the antitumor activity and safety as first-line treatment of patients with advanced NSCLC. It was concluded that as a single-agent, docosahexaenoic acid-paclitaxel has little activity in patients with advanced NSCLC. But despite the low objective response rate, treatment was associated with survival comparable to that seen with standard platinum-based combination chemotherapy (Payne et al., 1998). The clinical trials database shows several phase II and phase III trials alone or in combination therapy. As a single agent, it is undergoing phase III trials against advanced lung cancers (NCT00249262) and phase II trials against advanced eye melanoma (NCT00244816) and advanced skin melanoma (NCT00249262). It is also undergoing phase III trials in combination therapy with carboplatin for the treatment of advanced skin melanoma (NCT00243867).

Larotaxel (XPR9881 14, Sanofi-Aventis), a cyclopropyl derivative is undergoing several trials alone or in combination therapy. Its phase I study in combination with carboplatin in chemotherapy-naïve patients with stage IIIB or stage IV NSCLC has been reported and this combination was showing modest activity in chemotherapy-naïve patients with advanced/metastatic NSCLC (Robert et al., 2010). Phase II multicenter study of larotaxel (XRP9881), in patients with MBC who previously received taxane-based therapy concluded its good activity, manageable toxicity, and a favourable therapeutic index in women with taxane-pre-treated MBC (Diéras et al., 2008). The clinical trials database is showing several phase II and phase III trials in combination therapy. These include phase II trials in combination with docetaxel and trastuzumab against breast cancer (NCT00485979) and phase III trials in combination with cisplatin versus gemcitabine/cisplatin in the first line treatment of locally advanced/metastatic urothelial tract or bladder cancer (NCT0062564).

Ortataxel (BAY-59-862, 15), a new-generation taxane, is active in tumor models resistant to paclitaxel and docetaxel and elicits responses in taxane-resistant NSCLC. In its phase II study against taxane resistant breast cancers, ortataxel showed encouraging activity and clinical benefit in breast cancer patients who are resistant to paclitaxel or docetaxel combinations (Beer and Lenaz, 2008). The clinical trials database is showing three phase II trials, one is for the treatment of NSCLCs (NCT00054314). The other two are in treatment of advanced kidney cancer (NCT00039169) and refractory Non Hodgkin’s lymphoma (NCT00039156). TPI-287 (Tapestry Pharmaceuticals, 16) is reported to be undergoing phase I/II study in combination with temozolomide for the treatment of melanoma (NCT01067066), phase I/II study for safety and efficacy study in the treatment of neuroblastoma and medulla blastoma (NCT01483820), a randomised efficacy study to treat primary refractory or early relapsed neuroblastoma (NCT01505608) and is also undergoing phase II studies to treat breast cancer 
metastatic to the brain (Fitzgerald et al., 2012; http://www.clinicaltrials.gov/ct2/show/NCT01332630). Unlike the other taxanes, TPI-287 is permeable through the BBB.

Milataxel (MAC-321 17, Taxolog) completed phase II trials for colorectal cancer in 2009, but has been discontinued due to toxicity issues at the dose level $35 \mathrm{mg} / \mathrm{m}^{2}$ (Ramanathan et al., 2008). Tesetaxel (DJ-927, 18) has been undergoing 14 phase I/II clinical trials alone or in combination therapy with other drugs against various cancer types (http://clinicaltrialsfeeds.org/clinical-trials/results/term=Tesetaxel; Saif et al., 2011). BMS275183 (19), an oral C-4 methyl carbonate analogue of paclitaxel was undergoing phase I studies in order to (i) assess the safety and tolerability of BMS-275183, and (ii) determine a suitable phase II dose of the drug when given on a continuous daily schedule to patients with advanced solid tumours. Unfortunately the lack of evidence showing clinical benefit and the occurrence of two fatal events of neutropenic sepsis, coupled with high drug exposure, led to the discontinuation of its further development (Heath et al., 2011). BMS-275183 is also undergoing randomized, phase II study in patients with pre-treated NSCLC (NCT00099879). Another taxane derivative, BMS-184476 (Bristol-Myers-Squibb, 20), a 7-methylthiomethyl ether derivative of paclitaxel displays potency superior to paclitaxel against tumor cells in culture and human tumor xenografts. It also inhibits the growth of paclitaxel-resistant human tumor cell lines with multidrug resistance mediated by either P-glycoprotein or mutated tubulin (Plummer et al., 2002). It has been undergoing phase I trials to study its effectiveness in treating patients who have advanced solid tumors. RPR 109881A (21) is another taxane derivative containing a cyclopropyl ring. Its activity was assessed in a variety of murine and human tumour lines in vitro and in vivo and compared with docetaxel, RPR 109881A was active against tumours sensitive to docetaxel (Gelmon et al., 2000). It has been in phase III studies to determine if RPR 109881A is a better treatment than capecitabine (Xeloda) for advanced breast cancer in patients that no longer benefit from docetaxel and/or paclitaxel (http:// www.clinicaltrials.gov/ct2/show/ NCT00081796). Several other taxane derivatives are in clinical development and include albumin-bound paclitaxel, albumin-bound docetaxel, paclitaxel microspheres and many others (Hennenfent and Govindan, 2006).

\section{Podophyllotoxin and its semisynthetic analogues}

Podophyllotoxin (22), obtained from Podophyllum peltatum, is another important anti-cancer compound (Imbert, 1998). Some 30 years after its discovery, it was demonstrated that this compound binds reversibly to tubulin (Wilson et al., 1975) and therefore had potential as an 
anticancer agent. Etoposide (23) and teniposide (24) are the two key analogs of podophyllotoxin. Instead of acting as the microtubule inhibitors in the same manner as the lead compound, these derived drugs exert their anticancer activity by acting as inhibitors of the enzyme topoisomerase II and are, therefore useful in the treatment of various cancers (Srivastava et al., 2005; Odwyer et al., 1985). The impressive potency and clinical efficacy of the two analogues has prompted extensive structure activity studies based on the podophyllotoxin prototype and numerous podophyllotoxin analogues have been synthesised and evaluated since the 1950s to overcome the problems such as poor water solubility, acquired drug resistance and metabolic inactivation met by parent molecule. Several semisynthetic analogues like NK-611, GL-331, azatoxin, Top-53, etoposide phosphate and tafluposide have been produced as either clinical drugs or novel clinical trial candidates for various cancers Hanauske et al., 1995; Mross et al., 1996; Liu et al., 2002; Huang et al., 2000; Cline et al., 1997; Hande, 1998; Zhang and Trissel, 1999; Sargent et al., 2003).

\section{Camptothecin and its semisynthetic analogues}

Camptothecin (CPT) (25), a quinoline alkaloid with topoisomerase-I inhibitor activity isolated from Camptotheca acuminata, induces cell death by DNA damage (Hsiang et al., 1985). It was however withdrawn from clinical trials because of its low aqueous solubility and severe toxicity. To overcome these limitations, a number of CPT analogues were synthesized and approved for clinical use such as topotecan (26), irinotecan (27) and belatecan (28) which effectively inhibit DNA topoisomerase-I, a critical enzyme in DNA replication and transcription (Oberlies and Kroll, 2004).

Another semisynthetic CPT derivatives 9-aminocamptothecin (9-AC, 29), showed potent activity in preclinical studies, but has not demonstrated clinically useful antitumor activity to date. It entered phase I trials in 1993 and demonstrated predictable dose dependent myelosupression as its major toxicity. However, in subsequent phase II trials, despite showing modest activity in ovarian and malignant lymphoma, the drug was not found to be active against lung cancer or colon cancer on any schedule. Thus it was dropped from further development in 1999 (Pazdur et al., 1997; Vey et al., 1999). However it has been undergoing several phase I/II studies to determine its safety, efficacy and tolerability alone or in combination studies with other drugs (Farray et al., 2006). Karenitecin (BNP-1350, 30), another semi synthetic analogue of CPT has been used in phase II trials against malignant melanoma (Adil et al., 2005; http:/www.clinicaltrials.gov/ct2/show/NCT00062491) and in phase II in treatment of patients with brain tumours (NCT00062478). Diflomotecan (BN- 
80915, 31) is an E-ring modified CPT analogue, which possesses greater lactone stability in plasma compared with other topoisomerase I inhibitors and was the first homo CPT to enter into development. As of 2007 it has been undergoing phase I clinical trials against solid tumours (Scott et al., 2007). A phase II open label study investigating the activity of diflomotecan (BN80915) administered at the fixed dose of 7mg as a 20 minute intravenous infusion once every 3 weeks in patients with sensitive small cell lung cancer (SCLC) who have failed first-line treatment with a platinum based regimen has been completed by Ipsen pharmaceuticals (http://clinicaltrialsfeeds.org/clinical-trials/show/NCT00080015).

Gimatecan (ST-1481, 32), an oral topoisomerase I inhibitor, has been reported to be in phase I for the treatment of patients with advanced solid tumours (Zhu et al., 2009) and phase II for the treatment of recurrent epithelial ovarian and fallopian tube cancers, previously treated with platinum and taxanes (Pecorelli et al., 2010). Elomotecan (BN-80927, 33), an inhibitor of topoisomerase I and II, is in phase I trials against advanced solid tumours by Ipsen and Roche pharmaceuticals (Trocóniz et al., 2012). DRF-1042 (34) a novel, orally active camptothecin analogue, has completed phase I clinical trials by Dr Reddys Laboratories (http://www.evaluategroup.com/Universal/View.aspx?type=Story\&id=29649). Exatecan mesylate (35) has been in phase II trials for the treatment of gastric cancers (Ajani et al., 2005), and the treatment of children with relapsed or refractory rhabdomyosarcoma. (http://clinicaltrialsfeeds.org/clinical-trials/show/NCT00055939). Rubitecan (36) exists as an equilibrium form of 9-nitro-camptothecin (9-NC) and 9-amino-camptothecin (9-AC). It is a metabolite that was thought to be active though it failed in clinical trials showing unsatisfactory activity against a number of other solid tumours in relatively small phase I/II trials (Clark, 2006). Rubitecan did however show promising activity against pancreatic cancer, and was advanced into phase III clinical trials but based on unfavourable results an application for FDA approval by SuperGen, the company developing the drug was withdrawn (http://www.prnewswire.com/news-releases/supergen-announces-withdrawal-of-orathecintmnda-53822397.html).

Besides this, various conjugated CPT analogues have been developed by conjugating small molecules at the C-20 hydroxyl which leads to stabilisation of the lactone ring delaying its opening and reducing affinity to serum albumin. Also the prodrug approach leads to a slow release of the active drug form which can dramatically alter the therapeutic index of CPTs. Various conjugated CPT analogues have been developed and some have reached clinical trials. 
CZ-48 (37), which is a 20-O-alkyl ester of CPT, is currently in phase I for the treatment of solid tumours (http://stehlin.org/cz48/). TP-300 (38) is undergoing phase I trials against advanced solid tumours (Anthoney et al., 2012). EZN-2208 (39) is undergoing phase I studies in patients with advanced malignancies (Kurzrock et al., 2012).

Co-polymers have also been used as prodrugs of CPTs. MAG-CPT is a copolymer linked to CPT through a glycylaminohexanoyl-glycyl spacer which was developed by Pharmacia and Upjohn in an attempt to overcome problems associated with the delivery of CPT. Unfortunately because of toxicity issues, its development was discontinued after phase I (Bissett et al., 2004). XMT-1001 is a prodrug in which CPT is attached to poly (1-hydroxy methyl ethylene hydroxy methyl formyl) and is being evaluated in an ongoing phase $1 \mathrm{~b}$ clinical trial targeting lung cancers, following successful completion of a phase 1 clinical trial. Phase 2 clinical trials for XMT-1001 are planned for treatment of lung cancers (http://www.mersana.com/product-pipeline/xmt-1001.php). CRLX-101 is a nano pharmaceutical comprised of the chemotherapeutic camptothecin (CPT) conjugated to a linear, cyclodextrin-based polymer. CRLX-101 is designed to increase the exposure of tumor cells to CPT while minimizing side effects. Phase I/II trials of this prodrug are being conducted to determine the safety, toxicity, and the maximum tolerated dose (MTD) of CRLX-101 when administered intravenously to subjects with advanced solid tumors (http://www.clinicaltrials.gov/ct2/show/NCT00333502). In addition to this, nanoparticle encapsulation and liposomal core loading are being investigated to help optimise the delivery of CPT and some have already reached clinical trials. Irinotecan (CPT-11) encapsulated has been developed by Neo Pharma and Pharma engine; it is an oncology drug product consisting of the active metabolite of irinotecan (CPT-11) encapsulated, a known anticancer drug, encapsulated in a liposome. The irinotecan liposome formulation is currently in phase I trials in the treatment of advanced cancers (http://www.clinicaltrials.gov/ct2/show NCT00046540?term=cancer\&intr=cpt-11+liposomal\&rank=4). Formulation of relatively insoluble analogues of CPT for their improvement in drug delivery (pharmacodynamic profile) may be obtained with liposomal formulations. Such formulations may lead to improved safety and efficacy profiles, when compared with the pro-drug CPT.

\section{Combretastatin and its analogues}

Combretastatins have been isolated from the bark of the South African tree Combretum caffrum Kuntze (Combretaceae). Combretastatin A4 (40) is active against colon, lung and 
leukaemia cancers. The combrestatin A series is historically known for its remarkable biological activity in terms of inhibition of tubulin assembly and in vitro cytotoxicity against human cancer cell lines. CA-4P (41) and CA-1P (42) which binds at the colchicine site of $\beta$ tubulin are among the most active prodrugs of the natural products isolated from C. caffrum (Cirla and Mann, 2003). A number of phase I/II trials have been done on CA-4P which focussed on establishing the safety and tolerability of its combination with other treatment regimen like chemotherapy, radiotherapy and antiangiogenic therapies (Nathan et al., 2012). These studies showed that CA-4P can be safely combined with a number of other conventional therapies and has lead to the initiation of phase II studies in NSCLC and anaplastic thyroid cancer (http://www.clinicaltrials.gov/ct2/show/NCT00653939).

The phosphate prodrug of combretastatin A-1 (CA-1P, OXi4503) has shown excellent activity in preclinical studies and has entered in 7 clinical trials. Two clinical studies are currently underway using OXi-4503. One is in phase I study evaluating the safety and tolerability in patients with AML (NCT01085656). The second study is in phase IIb to study its safety and efficacy against solid tumour growing in liver (Patterson et al., 2012). OXiGENE announced that OXi4503 has been granted orphan designation by the US FDA for the treatment of AML (http://www.marketwatch.com/oxigene-announces-oxi4503-grantedorphan-designation-for-treatment-of-accute-myelogenous-leukemia-2012-11-21).

\section{Other plant derived anticancer agents}

7.1 Omacetaxine mepesuccinate (or homoharringtonine 43, trade name Synribo, made by Teva Pharmaceutical Industries Ltd) is an alkaloid from Cephalotaxus harringtonia. On October 26, 2012, the FDA granted accelerated approval to omacetaxine mepesuccinate as subcutaneous use for the treatment of adult patients with chronic- or accelerated-phase CML, with resistance and/or intolerance to two or more tyrosine kinase inhibitors (TKIs). Omacetaxine is a protein translation inhibitor. It inhibits protein translation by preventing the initial elongation step of protein synthesis (Wetzler and Segal, 2011). It interacts with the ribosomal A-site and prevents the correct positioning of amino acid side chains of incoming aminoacyl-tRNAs.

7.2 Ingenol mebutate (ingenol-3-angelate 44, trade name Picato) is a substance found in the sap of the plant Euphorbia peplus (Fallen et al., 2012). A gel form of the compound was approved for use by the US FDA and EMA in January 2012 for the treatment of acid 
keratosis. The substance is an ester of diterpene and angelic acid and is marketed by LEO pharma.

7.3 Betulinic acid (45), a naturally occurring pentacyclic triterpenoid, is a common secondary metabolite of plants, primarily from Betula species (Betulaceae) (Cichewitz et al., 2004). Betulinic acid was isolated from Zizyphus species, e.g. Mauritiana rugosa and M. oenoplia (Pisha et al., 1995; Shoeb, 2006) and exhibits various biological activities, such as anti-HIV, anti-inflammatory, antioxidant, antiretroviral and antibacterial properties (Fujioka et al., 1994; Nguemfo et al., 2009; Tzakos et al., 2012; Onwuchekwa and Oluwole, 2011; Yogeeswari et al., 2005). Mostly recently, it has been employed as a potential anticancer agent by inhibition of topoisomerase (Chowdhury et al., 2002; Mukherjee et al., 2006; Fulda and Debatin, 2005; Mullauer et al., 2010; Fulda, 2009). A large number of betulinic acid derivatives have been developed to increase its therapeutic activity. But development of betulinic acid derivatives for clinical use has been hampered by adverse pharmacological and physico-chemical characteristics of this class of compounds. One novel, well tolerated BetA derivative is NVX-207, which showed significant anti-tumor activity in clinical studies in canine cancer patients with treatment-resistant malignancies. NVX-207-induced apoptosis was associated with activation of the intrinsic apoptotic pathway via cleavage of caspases -9 , $-3,-7$ and of poly (ADP-ribose) polymerase (PARP). A phase I/II study in dogs suffering from naturally occurring cancer receiving local treatment of NVX-207 (10 mg mL $\left.{ }^{-1}\right)$ showed excellent clinical responses including a complete remission in so far 5/5 treated animals (Willmann et al., 2009).

7.4 Flavopiridol (46) is totally synthetic, but its chemical structure is based on identical to a product rohitukine obtained from Dysoxylum binectariferum, a plant indigenous to India (Naik et al., 1988). Flavopiridol was one of the over 100 analogs synthesized during structure-activity studies, Its mechanisms of action remain incompletely defined but include targeting of cyclin dependent kinases including the CDK9/cyclin T complex (Chao and Price, 2001; Chao et al., 2000; de Azevedo et al., 2002; Lam et al., 2001) down regulation of Mcl-1 and other antiapoptotic proteins (Gojo et al., 2002; Kitada et al., 2000) induction of mitochondrial permeability changes (Hussain et al., 2008) and other. Originally synthesized and supplied by Hoechst India Limited, flavopiridol is provided to the Division of Cancer Treatment and Diagnosis of the National Cancer Institute (NCI) by Aventis Pharmaceuticals, Inc. Flavopiridol is the first potent inhibitor of cyclin-dependent kinases (cdks) to reach 
clinical trial (Geoffrey and Shapiro, 2004). It is currently undergoing several phase I and phase II clinical trials, either alone or in combination with other anticancer agents, against a broad range of tumors, including leukemias, lymphomas and solid tumors.

7.5 Curcumin (47) is a polyphenol derived from the Curcuma longa plant, commonly known as turmeric. Turmeric contains a class of compounds known as the curcuminoids, comprised of curcumin, demethoxycurcumin and bis-demethoxycurcumin. Curcumin is the principal curcuminoid and comprises approximately 2-5\% of turmeric; it is responsible for the yellow color of the spice as well as the majority of turmeric's therapeutic effects (Wilken et al., 2011). It has a variety of therapeutic properties including anti-oxidant, analgesic, antiinflammatory and antiseptic activity (Akram et al., 2010). More recently curcumin has been found to possess anti-cancer activities via its effect on a variety of biological pathways involved in mutagenesis, oncogene expression, cell cycle regulation, apoptosis, tumorigenesis and metastasis (Wilken et al., 2011). Phase IIa clinical trial of curcumin is going on for the prevention of colorectal neoplasia (Carroll et al., 2011). In addition it is also undergoing several phase I and II trials against several solid tumours.

Besides these, a large number of other anticancer agents isolated from plants are listed in Table 1.

Table 1: Other anticancer agents derived from terrestrial plants

\begin{tabular}{|c|c|c|c|c|}
\hline Name & Source & Target & inical status & Ref \\
\hline Berbamine & Berberis amarensis & caspase-3-dependent apoptosis & Lead molecule & Liang et al., 2009; Kapoor, 2012 \\
\hline Berberine & Hvdrastis canadensis & - & Lead molecule & Diogo et al., 2011; \\
\hline Bruceantin & Brucea antidysenterica & Inhibits peptidyl transferase elongation reaction & $\begin{array}{l}\text { Clinical development } \\
\text { terminated }\end{array}$ & \\
\hline $\begin{array}{l}\text { Beta Lapachone(ARQ- } \\
\text { 501) }\end{array}$ & Tabebuia avellanedae & topoisomerase I\&II & Phase II & Cragg et al., 2005;Blanco et al, 2011 \\
\hline Colchicine & Colchium automole & anti-mitotic & Lead molecule & Bhattacharyya et al., 2008 \\
\hline Diadzein \&Genistein & Lupinus species & inhibits 3A 4-mediated metabolism & Phase II & Jung et al., 2012;Messing et al., 2012 \\
\hline $\begin{array}{l}\text { Dimethyl xanthene-9-on- } \\
\text { 4-acetic acid (DMXAA) }\end{array}$ & $\begin{array}{l}\text { Flavone-8-acetic acid } \\
\text { analog }\end{array}$ & TNF-á induction & Phase I/II & Daniel et al., 2012; Buchanan et al., 2012 \\
\hline Ellipticine & Ochrosia borbonia & topoisomerase II inhibitor & Lead molecule & Iveta et al., 2013; Marie et al., 2012 \\
\hline 4-Ipomeanol & Ipomoea batatas & DNA binding & Lead molecule & Lakhanpal et al., 2001 \\
\hline Kanglaite & Coix lachryma-jobi & Inhibits mitosis of tumor cells during $\mathrm{G}_{2} / \mathrm{M}$ phase & seLead molecule & Zhan et al., 2012 \\
\hline Meisoindigo & Indigofera tinctoria & Induces apoptosis by locking Stat 3 signaling & CD terminated & Lee et al.,2010 \\
\hline Phenoxodiol & plant isoflavone genistein & $\begin{array}{l}\text { inhibits plasma membrane electron transport \& } \\
\text { cell proliferation }\end{array}$ & Phase I & Simon et al., 2012 \\
\hline Perillyl alcohol & Limonene analogue & Activates capase 3 apoptosis & Phase I & Garcia et al., 2010;Farazuddin et al., 2012 \\
\hline Pervilleine A & Erthroxylum porvillei & inhibition of P-glycoprotein & Lead molecule & Mi et al., 2003 \\
\hline Roscovitine (CYC 202) & $\begin{array}{l}\text { Olomucine (Raphanus } \\
\text { sativus }\end{array}$ & CDK inhibitor & Phase II & Slovackova et al., 2012; Foell et al., 2008 \\
\hline Silvestrol & Aglaia foveolata & trigers mitochondrial pathway of apoptosis & Lead molecule & Kim et al., 2007 \\
\hline Santonin & Artemisia maritima & Inhibition of NF-Kb & Lead molecule & Khazir et al., 2013 \\
\hline
\end{tabular}




\section{Conclusion}

Anticancer agents discovered from plants have played an important role in the treatment of cancer. Compounds derived from plants may not serve directly as drugs, but they provide leads for the development of potential anticancer agents. Plant derived compounds such as paclitaxel, camptothecin, and podophylotoxin have significantly influenced cancer research on many aspects. They have helped the researchers to understand the disease better, provided new and efficient therapies possessing new mechanisms of action, opened new research avenues, and provided new inspiration in the development of new and future anticancer drugs. Plants represent an enormous diversity on earth, but only a small portion of that has been yet explored. So it is anticipated that plants can provide potential bioactive compounds for the development of leads against various diseases indeed far greater than compounds achievable by synthesis.

With the fast recognition of novel proteins having significant regulatory effects on tumor cell cycle progression, and their conversion into targets for high throughput screening, molecules isolated from plants and other natural sources are proving to be an important basis of novel inhibitors of the action of these key proteins, and have the potential for development into selective anti-cancer agents.

\section{Acknowledgements}

Authors are thankful to Prof. Egmont Rohwer (Head, Department of Chemistry) and Prof. Don A Cowan (Director, Genomics Research Institute and Centre for Microbial Ecology and Genomics) University of Pretoria for their valuable help and support. Thanks are also due to Dr. Pieter De-Maayer, CMEG for editing the manuscript. We also acknowledge University of Pretoria for Postdoctoral fellowship to JK and BAM.

\section{References}

1. Adil, D., Nikola, V., Barbara, C., Jennifer, D., Patricia, S., Pamela, M., Patricia, U., Ronald, C. D., Elmer, B., Zhenmei, L., Frederick, H., Daniel, S., 2005. Phase II Trial of Karenitecin in Patients with Malignant Melanoma: Clinical and Translational Study. Clin. Cancer Res.11, 3009-3016.

2. Ajani, J.A., Takimoto, C., Becerra, C.R., Silva, A., Baez, L., Cohn, A., Major, P., Kamida, M., Feit, K., De Jager, R., 2005. A phase II clinical and pharmacokinetic study of intravenous exatecan mesylate (DX-8951f) in patients with untreated metastatic gastric cancer. Invest. New Drug. 23, 479-84. 
3. Akram, M., Shahab-Uddin., Afzal, A., Usmanghani, K., Hannan, A., Mohiuddin, E Asif, M., 2010. Curcuma longa and Curcumin: A review article. Rom. J. biol. -Plant biology 55, 65-70 (http://www.ibiol.ro/plant/volume\%2055/art201.pdf).

4. Anand, C., Neetu, S., 2011. Contribution of world health organization in the global acceptance of Ayurveda. J. Ayurveda Integr. Med. 2, 179-186.

5. Anthoney, D.A., Naik, J., Iain, R.J., Mac, P., Donna, C., John, M. H., Janet, A. H., Tomohisa, S., Masaichi, A., Keith, J., Masanori, M., Christopher, T., Evans, T.R.J., 2012. Phase I study of TP300 in patients with advanced solid tumors with pharmacokinetic, pharmacogenetic and pharmacodynamic analyses. BMC Cancer.12, 536.

6. Bao, R., Pokman, C., 2011. Novel compounds in the treatment of lung cancer current and developing therapeutic agents. J. Exper. Pharm. 3, 21-34.

7. Beaulieu, E., Demeule, M., Ghitescu, L., Beliveau, R., 1997. Glycoprotein is strongly expressed in the luminal membranes of the endothelium of blood vessels in the brain. Biochem. J. 326, 539-544.

8. Beer, M., Lenaz, D. A., 2008. Phase II study of ortataxel in taxane-resistant breast cancer. J. Clin. Oncology 26, 1066.

9. Bennouna, J., Delord, J.P., Campone, M., Nguyen, L., 2008. Vinflunine: a new microtubule inhibitor agent. Clin. Cancer Res. 14, 1625-1632.

10. Bhattacharyya, B., Panda, D., Gupta, S., Banerjee, M., 2008. Anti-mitotic activity of colchicine and the structural basis for its interaction with tubulin. Med. Res. Rev. 28, 155-83.

11. Bissery, M.C., Nohynek, G., Sanderink, G.J et al., 1995. Docetaxel (Taxotere): A review of preclinical and clinical experience, Part 1-Preclincial experience. Anticancer Drug. 6, 339-368.

12. Bissett, D., Cassidy, J., Bono, J. S de., Muirhead, F., Main, M., Robson, L., Fraier, D., Magnè, M. L., Pellizzoni, C., Porro, M.G., Spinelli, R., Speed, W., Twelves, C., 2004. Phase I and pharmacokinetic (PK) study of MAG-CPT (PNU 166148): a polymeric derivative of camptothecin (CPT). Br. J. Cancer 91, 50-55.

13. Blanco, E., Bey, E.A., Khemtong, C., Yang, S.G., Setti-Guthi, J., Chen, H., Kessinger, C.W., Carnevale, K.A., Bornmann, W.G., Boothman, D.A., Gao, J., 2010. Betalapachone micellar nanotherapeutics for non-small cell lung cancer therapy. Cancer Res. 70, 3896-904. 
14. Buchanan, C.M., Shih, J.H., Astin, J.W., Rewcastle, G.W., Flanagan, J.U., Crosier, P.S., Shepherd, P.R., 2012. DMXAA (Vadimezan, ASA404) is a multi-kinase inhibitor targeting VEGFR2 in particular. Clin. Sci (Lond). 122, 449-57.

15. Budman, D.R., 1992. New vinca alkaloids and related compounds. Semin. Oncol. 19, 639-45.

16. Butler, M. S., 2008. Natural products to drugs: natural product-derived compounds in clinical trials. Nat. Prod. Rep. 25, 475-516.

17. Carroll, R.E., Benya, R.V., Turgeon, D.K., Vareed, S., Neuman, M., Rodriguez, L., Kakarala, M., Carpenter, P.M., McLaren, C., Meyskens, F.L. Jr., Brenner, D.E., 2011. (Phila). 2011. Phase IIa clinical trial of curcumin for the prevention of colorectal neoplasia. Cancer Prev. Res. 4, 354-64.

18. Channing, J. P., Emmanuel, S. A., 2011. Cabazitaxel: a novel second-line treatment for metastatic castration-resistant prostate cancer. Drug Des. Devel. Ther. 5, 117-124.

19. Chao, S.H., Fujinaga, K., Marion, J.E., Taube, R., Sausville, E.A., Senderowicz, A.M et al., 2000. Flavopiridol inhibits P-TEFb and blocks HIV-1 replication. J. Biol. Chem. 275, 28345-8.

20. Chao, S.H., Price, D.H., 2001. Flavopiridol inactivates P-TEFb and blocks most RNA polymerase II transcription in vivo. J. Biol. Chem. 276, 31793-9.

21. Chowdhury, A.R., Mandal, S., Mittra, B., Sharma, S., Mukhopadhyay, S., Majumder, H.K., 2002. Betulinic acid, a potent inhibitor of eukaryotic topoisomerase I: Identification of the inhibitory step, the major functional group responsible and development of more potent derivatives. Med. Sci. Monitor. 8, 254-265.

22. Cichewitz, R.H., Kouzi, S.A., 2004. Chemistry, biological activity, and chemotherapeutic potential of betulinic acid for the prevention and treatment of cancer and HIV infection. Med. Res. Rev. 24, 90-114.

23. Cirla, A., Mann, J., 2003. Combrestatins: from natural product to drug discovery. Nat. Prod. Rep. 20, 558-564.

24. Clark, J.W., 2006. Rubitecan. Expert Opin. Investig. Drug. 15, 71-9.

25. Cline, S.D., Macdonald. T.L., Osheroff, N., 1997. Azatoxin is a mechanistic hybrid of the topoisomerase II-targeted anticancer drugs etoposide and ellipticine. Biochemie. 36, 13095-101.

26. Cragg, G.M., Newman, D.J., 2005. Plants as a source of anticancer agents. J. Ethnopharmacol. 100, 72-79. 
27. Daniel, P., , Wendy, L.; Mark, S. W., Shruti, S., Katherine, A. F., Stefanie N. V., 2012. 5,6-Dimethylxanthenone-4-acetic acid (DMXAA) activates Stimulator of Interferon Gene (STING)- dependent innate immune pathways and is regulated by mitochondrial membrane potential. J. Biol. Chem. 287, 39776-88.

28. De Azevedo, W.F., Jr Canduri, F., da Silveira, N.J., 2002. Structural basis for inhibition of cyclindependent kinase 9 by flavopiridol. Biochem. Biophys. Res. Commun. 293, 566-71.

29. Diéras, V., Limentani, S., Romieu, G., Tubiana-Hulin, M., Lortholary, A., Kaufman, P., Girre, V., Besenval, M., Valero, V., 2008. Phase II multicenter study of larotaxel (XRP9881), a novel taxoid, in patients with metastatic breast cancer who previously received taxane-based therapy. Ann. Oncol. 19, 1255-60.

30. Diogo, C.V., Machado, N.G., Barbosa, I.A., Serafim, T.L., Burgeiro, A., Oliveira, P.J., 2011 Berberine as a promising safe anti-cancer agent - is there a role for mitochondria. Curr. Drug Targets. 12, 850-9.

31. Fallen, R.S., Gooderham, M., 2012. Ingenol mebutate: An introduction. Skin Therapy Lett. 17, 1-3.

32. Farazuddin, M., Sharma, B., Khan, A.A., Joshi, B., Owais, M., 2012. Anticancer efficacy of perillyl alcohol-bearing PLGA micro-particles. Int. J. Nanomedicine. 7, 3547.

33. Farray, D., Ahluwalia, M.S., Snyder, J., Barnett, G.H., Cohen, B.H., Suh, J.H., Peereboom, D.M., 2006. Pre-irradiation 9-amino [20s] camptothecin (9-AC) in patients with newly diagnosed glioblastoma multiforme. Invest. New Drug. 24, 177-80.

34. Fellner, S., Bauer, B., Miller, D. S., Schaffrik, M., Fankhanel, M., Spruss, T., Bernhardt, G., Graeff, C., Farber, L., Gschaidmeier, H., Buschauer, A., Fricker, G. et al., 2002. Transport of paclitaxel (Taxol) across the blood-brain barrier in vitro and in vivo. J. Clin. Invest. 110, 1309-1318.

35. Fitzgerald, D.P., Emerson, D. L., Qian, Y., Anwar, T., Liewehr, D. J., Steinberg, S.M., Silberman, S., Palmieri, D., Steeg, P.S., 2012. TPI-287, a new taxane family member, reduces the brain metastatic colonization of breast cancer cells. Mol. Cancer Ther. 11, 1959-67.

36. Fujioka, T., Kashiwada, Y., Kilkuskie, R.E., Cosentino, L.M., Ballas, L.M., Jiang, J.B., Janzen, W.P., Chen, I.S., Lee, K.H., 1994. Betulinic acid and platanic acid as anti-HIV principles from Syzigium claviflorum, and the anti-HIV activity of structurally related triterpenoids. J. Nat. Prod. 57, 243-247. 
37. Fulda, S., 2009. Betulinic acid: a natural product with anticancer activity. Mol. Nutr. Food Res. 53, 140-146.

38. Fulda, S., Debatin, K.M., 2005. Sensitization for anticancer drug-induced apoptosis by betulinic acid. Neoplasia. 7, 162-170.

39. Garcia, D.G., Amorim, L.M., de Castro, F.M.V., Freire, A.S., Santelli, R.E., Da Fonseca, C.O., Quirico-Santos, T., Burth, P., 2010. The anticancer drug perillyl alcohol is a Na/K-ATPase inhibitor. Mol. Cell Biochem. 345, 29-34.

40. Gelmon, K.A., 1994. The Taxoids: paclitaxel and docetaxel. Lancet. 344, 1267-1272.

41. Shapiro, G.I., 2004. Preclinical and Clinical Development of the Cyclin-Dependent Kinase Inhibitor Flavopiridol. Clin. Cancer Res. 10, 4270-4275.

42. Gojo, I., Zhang, B., Fenton, R.G., 2002. The cyclin dependent kinase inhibitor Flavopiridol induces apoptosis in multiple myeloma cells through transcriptional repression and down-regulation of Mcl-1. Clin. Cancer Res. 8, 3527-38.

43. Haag, R., Kratz, F., 2006. Polymer therapeutics: Concepts and applications. Angew. Chem. Int. Edit. 45, 1198-1215.

44. Hanauske, A. R., Wüster, K.C., Lehmer, A., Rotter, M., Schneider, P., Kaeser-Fröhlich, A., Rastetter, J., Depenbrock, H., 1995. Activity of NK 611, a new epipodophyllotoxin derivative, against colony forming units from freshly explanted human tumours in vitro. Eur. J. Cancer. 31A, 1677-81.

45. Hande, K. R., 1998. Etoposide: Four decades of development of a topoisomerase II inhibitor. Eur. J. Cancer. 34, 1514-1521.

46. Heath, E.I., Lorusso, P., Ramalingam, S.S., Awada, A., Egorin, M.J., Besse-Hamer, T., Cardoso, F., Valdivieso, M., Has, T., Alland, L., Zhou, X., Belani, C.P., 2011. A phase 1 study of BMS-275183, a novel oral analogue of paclitaxel given on a daily schedule to patients with advanced malignancies. Invest. New Drug. 29, 1426-31.

47. Hennenfent, K. L., Govindan, R., 2006. Novel formulations of taxanes: a review. Old wine in a new bottle. Annal. Oncol. 17, 735-749.

48. Hsiang, Y. H., Hertzberg, R., Hecht, S., Liu, L.F., 1985. Camptothecin induces proteinlinked DNA breaks via mammalian DNA topoisomerase I. J. Biol. Chem. 260, 14873-8.

49. Huang, T.S., Shu, C.H., Lee, C.C., Chen, L.T., Whang-Peng, J., 2000. In vitro evaluation of GL331's cancer cell killing and apoptosis-inducing activity in combination with other chemotherapeutic agents. Apoptosis 5, 79-85.

50. Hussain, S.R., Lucas, D.M., Johnson, A.J., Lin, T.S., Bakaletz, A.P., Dang, V.X et al., 2008. Flavopiridol causes early mitochondrial damage in chronic lymphocytic leukemia 
cells with impaired oxygen consumption and mobilization of intracellular calcium. Blood. 111, 3190-9.

51. Imbert, T.F., 1998. Discovery of podophyllotoxins. Biochimie. 80, 207-22.

52. Iveta, V., Michaela, M., Petr, H., Rene, K., Eva, F., Marie, S., 2013. The Anticancer Drug Ellipticine Induces Cytochromes P450 1A1, 1A2 and 3A, Cytochrome b5 and NADPH: Cytochrome P450 Oxidoreductase in Rat Liver, Kidney and Lung, Int. J. Electrochem. Sci. 8, 1586 - 1597.

53. Armstrong, J.G., Dyke, R.W., Fouts, P.J., Hawthorne, J.J., Jansen, C.J., Peabody, A.M., 1967. Initial Clinical Experience with Vinglycinate Sulphate, a Molecular Modification of Vinblastine. Cancer Res. 27, 221-227.

54. Ng, J.S., 2011. Vinflunine: review of a new vinca alkaloid and its potential role in oncology. J. Oncol. Pharm. Practice. 17, 209-224.

55. Jordan, M. A., Wilson, L., 2004. Microtubules as a target for anticancer drugs. Nat. Rev. Cancer. 4, 253-265.

56. Jordan, M.A., Thrower, D., Wilson, L., Thrower, D., Wilson, L., 1991. Mechanism of inhibition of cell proliferation by vinca alkaloids. Cancer Res. 51, 2212-2222.

57. Foell, J.L., Max, D., Giersberg, C., Korholz, D., Staege, M.S., 2008. Sensitivity of Hodgkin's Lymphoma Cell Lines to the Cell Cycle Inhibitor Roscovitine. Anti-cancer Res. 28, 887-894.

58. Jung,Y. L., Hee, S. K., Yong-Sang, S., 2012. Genistein as a Potential Anticancer Agent against Ovarian Cancer. J. Tradit. Complement Med. 2, 96-104 (http://www.jtcm.org/article.asp?issn=222-54110;year=2012;vol=2;issue=2;spage=96; epage=104; aulast=Lee).

59. Gelmon, K.A., Latreille, J., Tolcher, A., Genier, L., Fisher, B., Forand, D., D’Aloisio, S., Vernillet, L., Diagneault, L., Lebecq, A., Besenval, M., Eisenhauer, E., 2000. Phase I Dose-Finding Study of a New Taxane, RPR 109881A, Administered as a One-Hour Intravenous Infusion Days 1 and 8 to Patients With Advanced Solid Tumours. J. Clin. Oncology. 18, 4098-410.

60. Kemper, E. M., van Zandbergen, A. E., Cleypool, C., Mos, H. A., Boogerd, W., Beijnen, J. H., van Tellingen, O., 2003. Increased penetration of paclitaxel into the brain by inhibition of P-glycoprotein. Clin. Cancer Res. 9, 2849-2855.

61. Khazir, J., Singh, P.P., Doma, M.R., Syed, S., Hyder, I., Gousia, C., Ajay, M., Alam, M.S., Saxena, A.K., Arvinda, S., Gupta, B.D., Kumar, H.M.S., 2013. Synthesis and 
anti-cancer activity of novel spiro-isoxazoline and -isoxazolidine derivatives of $\alpha$ santonin. Eur. J. Med. Chem. 63, 279-289.

62. Kim, S., Hwang, B.Y., Su, B.N., Chai, H., Mi, Q., Kinghorn, A.D., Wild, R., Swanson, S.M., 2007. Silvestrol, a potential anticancer rocaglate derivative from Aglaia foveolata, induces apoptosis in $\mathrm{LNCaP}$ cells through the mitochondrial/apoptosome pathway without activation of executioner caspase-3 or -7. Anti-cancer Res. 27, 2175-83.

63. Kinghorn, A. D., Seo, E. K., 1996. Plants as sources of drugs. Acs. Sym. Ser. 647, 179-193.

64. Kitada, S., Zapata, J.M., Andreeff, M., Reed, J.C., 2000. Protein kinase inhibitors flavopiridol and 7-hydroxy-staurosporine down-regulate antiapoptosis proteins in B-cell chronic lymphocytic leukemia. Blood. 96, 393-7.

65. Kratz, F., Müller, I.A., Ryppa, C., Warnecke, A., 2008. Prodrug strategies in anticancer chemotherapy. Chem. Med. Chem. 3, 20-53.

66. Kruczynski, A., Barret, J.M., Etiévant, C., Colpaert, F., Fahy, J., Hill, B.T., 1998. (Antimitotic and tubulin-interacting properties of vinflunine, a novel fluorinated vinca alkaloid. Biochem. Pharmacol. 55, 635-648.

67. Kruczynski, A., Etiévant, C., Perrin, D., Chansard, N ., Duflos, A., Hill, B.T., 2002. Characterization of cell death induced by vinflunine, the most recent vinca alkaloid in clinical development. Br. J. Cancer. 86, 143-150.

68. Kurzrock, R., Goel, S., Wheler, J., Hong, D., Fu, S., Rezai, K., Morgan-Linnell, S.K., Urien, S., Mani, S., Chaudhary, I., Ghalib, M.H., Buchbinder, A., Lokiec, F., Mulcahy M., 2012. Safety, pharmacokinetics, and activity of EZN-2208, a novel conjugate of polyethylene glycol and SN38, in patients with advanced malignancies. Cancer. 118, 6144-51.

69. Lakhanpal, S., Donehower, R.C., Rowinsky, E.K., 2001. Phase II study of 4-ipomeanol, a naturally occurring alkylating furan, in patients with advanced hepatocellular carcinoma. Invest. New Drug. 19, 69-76.

70. Lam, L.T., Pickeral, O.K., Peng, A.C., Rosenwald, A., Hurt, E.M., Giltnane, J.M, et al., 2001. Genomic scale measurement of mRNA turnover and the mechanisms of action of the anti-cancer drug flavopiridol. Genome Biol. 2(10), research 0041.1-0041.11.

71. Langer, C.J., O'Byrne, K. J., Socinski, M. A., Mikhailov, S. M., Leśniewski-Kmak, K., Smakal, M., Ciuleanu, T.E., Orlov, S.V., Dediu, M., Heigener, D., Eisenfeld, A.J., Sandalic, L., Oldham, F.B., Singer, J.W., Ross, H.J., 2008. Phase III trial comparing paclitaxel poliglumex (CT-2103, PPX) in combination with carboplatin versus standard 
paclitaxel and carboplatin in the treatment of PS 2 patients with chemotherapy-naïve advanced non-small cell lung cancer. J. Thorac. Oncol. 3, 623-30.

72. Larkin, T., 1983. Herbs are often more toxic than magical. FDA consum. 1983, 17, 411.

73. Lee, C.C., Lin, C.P., Lee, Y.L., Wang, G.C., Cheng, Y.C., Liu, H.E., 2010. Meisoindigo is a promising agent with in vitro and in vivo activity against human acute myeloid leukemia. Leuk. Lymphoma. 51, 897-905.

74. Liang, Y., Xu, R.Z., Zhang, L., Zhao, X.Y., 2009. Berbamine, a novel nuclear factor kappaB inhibitor, inhibits growth and induces apoptosis in human myeloma cells. Acta. Pharmacol. Sin. 30, 1659-65.

75. Liu, J.M., Chen, L.T., Chao, Y., Li, A.F., Wu, C.W., Liu, T.S., Shiah, H.S., Chang, J.Y., Chen, J.D., Wu, H.W., Lin, W.C., Lan, C., Whang-Peng, J., 2002. Phase II and pharmacokinetic study of GL331 in previously treated Chinese gastric cancer patients. Cancer Chemother. Pharmacol. 49, 425-8

76. Lobert, S., Puozzo, C., 2008. Pharmacokinetics, metabolites, and preclinical safety of vinflunine. Semin. Oncol. (Suppl 3), S28-S33.

77. Mamtani, R., Vaughn, D.J., 2011. Vinflunine in the treatment of advanced bladder cancer. Expert Rev. Anticancer Ther. 11, 13-20.

78. Marie, S., Jitka, P., Eva, M., Jitka, U., Vilím, Š., Zdeněk, D., Eva, F., 2012. Ellipticine oxidation and DNA adduct formation in human hepatocytes is catalyzed by human cytochromes P450 and enhanced by cytochrome $b_{5}$. Toxicol. 302, 233-241.

79. Bachner, M., De Santis, M., 2008. Vinflunine in the treatment of bladder cancer. Ther. Clin. Risk Manag. 4, 1243-125.

80. Messing, E., Gee, J.R., Saltzstein, D.R., Kim, K., diSant'Agnese, A., Kolesar, J., Harris, L., Faerber, A., Havighurst, T., Young, J.M., Efros, M., Getzenberg, R.H., Wheeler, M.A., Tangrea, J., Parnes, H., House, M., Busby, J.E., Hohl, R., Bailey, H., 2012. A phase 2 cancer chemoprevention biomarker trial of isoflavone G-2535 (genistein) in pre-surgical bladder cancer patients. Cancer Prev. Res (Phila). 5, 621-30.

81. Mi, Q., Lantvit, D., Reyes-Lim, E., Chai, H., Pezzuto, J.M., Kinghorn, A.D., Swanson, S.M., 2003. Pervilleine F, a new tropane alkaloid aromatic ester that reverses multidrug resistance. Anti-cancer Res. 23, 3607-15.

82. Mross, K., Hüttmann, A., Herbst, K., Hanauske, A.R., Schilling, T., Manegold, C., Burk, K., Hossfeld, D.K., 1996. Pharmacokinetics and pharmacodynamics of the new 
podophyllotoxin derivative NK 611. A study by the AIO groups PHASE-I and APOH. Cancer Chemother. Pharmacol. 38, 217-24.

83. Mukherjee, R., Kumar, V., Srivastava, S.K., Agarwal, S.K., Burman, A.C., 2006. Betulinic acid derivatives as anticancer agents: structure activity relationship. Anticancer Agents Med. Chem. 6, 271-279.

84. Mullauer, F.B., Kessler, J.H., Medema, J.P., 2010. Betulinic acid, a natural compound with potent anticancer effects. Anti-Cancer Drug. 21, 215-227.

85. Shoeb, M., 2006. Anticancer agents from medicinal plants. Bangladesh J. Pharmacol. 1, $35-41$.

86. Naik, R.G., Kattige, S.L., Bhat, S.V., Alreja, B., De Souza, N.J., Rupp, R.H., 1988. An anti-inflammatory cum immune-modulatory piperidinylbenzopyranone from Dysoxylum binectariferum: isolation, structure and total synthesis. Tetrahedron 44, 2081-2086.

87. Nathan, P., Zweifel, M., Padhani, A.R., Koh, D.M., Ng, M., Collins, D.J., Harris, A., Carden, C., Smythe, J., Fisher, N., Taylor, N.J., Stirling, J.J., Lu, S.P., Leach, M.O., Rustin, G.J., Judson, I., 2012. Phase I trial of combretastatin A4 phosphate (CA4P) in combination with bevacizumab in patients with advanced cancer. Clin. Cancer Res. 18, 3428-39.

88. Nguemfo, E.L., Dimo, T., Dongmo, A.B., Azebaze, A.G., Alaoui, K., Asongalem, A.E., Cherrah, Y., Kamtchouing, P., 2009. Anti-oxidative and anti-inflammatory activities of some isolated constituents from the stem bark of Allanblackia monticola Staner L.C (Guttiferae). Inflammopharmacolocgy 17, 37-41.

89. Oberlies, N.H., Kroll, D.J., 2004. Camptothecin and taxol: historic achievements in natural products research. J. Nat. Prod. 67,129-35.

90. Odwyer, P.J., Leylandjones, B., Alonso, M.T., Marsoni, S., Wittes, R.E., 1985. Etoposide (VP-16-213). Current status of an active anticancer drug. N. Engl. J. Med. 312, 692-700.

91. Onwuchekwa, C., Oluwole, F.S., 2010. Anti-gastric ulcer and anti-inflammatory properties of betulinic acid in male albino rats. Sci. W. J. 5, 15-17 (http://www.scienceworldjournal.org/article/view/8567/6059).

92. Patterson, D.M ., Zweifel, M., Middleton, M.R., Price, P.M., Folkes, L.K., Stratford, M.R., Ross, P., Halford, S., Peters, J., Balkissoon, J., Chaplin, D.J., Padhani, A.R., Rustin, G.J., 2012. Phase I Clinical and Pharmacokinetic Evaluation of the Vascular Disrupting Agent OXi4503 in Patients with Advanced Solid. Clin. Cancer Res. 18, 1415-25. 
93. Payne, M., Ellis, P., Dunlop, D., Ranson, M., Danson, S., Schacter, L., Talbot, D., 1998. DHA-paclitaxel (Taxoprexin) as first-line treatment in patients with stage IIIB or IV non-small cell lung cancer: report of a phase II open-label multicenter trial. J. Thorac. Oncol. 1, 984-90.

94. Pazdur, R., Diaz-Canton, E., Ballard, W.P., Bradof, J.E., Graham, S., Arbuck, S.G., Abbruzzese, J.L., Winn, R., 1997. Phase II trial of 9-aminocamptothecin administered as a 72-hour continuous infusion in metastatic colorectal carcinoma. J. Clin. Oncol. 15, 2905-9.

95. Pecorelli, S., Ray-Coquard, I., Tredan, O., Colombo, N., Parma, G., Tisi, G., Katsaròs, D., Lhommé, C., Lissoni, A. A., Vermorken, J. B., Bois, A. Du., Poveda, A., Frigerio, L., Barbieri, P., Carminati, P., Brienza, S., Guastalla, J. P., 2010. Phase II of oral gimatecan in patients with recurrent epithelial ovarian, fallopian tube or peritoneal cancer, previously treated with platinum and taxanes. Ann. Oncol. 21, 759765.

96. Pisha, E., Chai, H., Lee, I.S., Chagwedera, T.E., Farnsworth, N.R., Cordell, G.A., Beecher, C.W., Fong, H.H., Kinghorn, A.D., Brown, D.M., Wani, M.C., Wall, M.E., Hieken, T.J., Das Gupta, T.K., Pezzuto, J.M., 1995. Discovery of betulinic acid as a selective inhibitor of human melanoma that functions by induction of apoptosis. Nat. Med. 1, 1046-51.

97. Plummer, R., Ghielmini, M., Calvert, P., Voi, M., Renard, J., Gallant, G., Gupta, E., Calvert, H., Sessa, C., 2002. Phase I and pharmacokinetic study of the new taxane analog BMS-184476 given weekly in patients with advanced malignancies. Clin. Cancer Res. 8, 2788-97.

98. Pourroy, B., Carré, M., Honoré, S., Bourgarel-Rey, V., Kruczynski, A., Briand, C., Braguer, D., 2004. Low concentrations of vinflunine induce apoptosis in human SK-NSH neuroblastoma cells through a postmitotic G1 arrest and a mitochondrial pathway. Mol. Pharmacol. 66, 580-591.

99. Kaur, R. Kapoor, K., Kaur, H., 2011. Plants as a source of anticancer agents. J. Nat. Prod. Plant Resour. 1, 119-124 (http://scholarsresearchlibrary.com/JNPPR-vol1iss1/JNPPR-2011-1-1-119-124.pdf).

100. Ramanathan, R.K., Picus, J., Raftopoulos, H., Bernard, S., Lockhart, A.C., Frenette, G., Macdonald, J., Melin, S., Berg, D., Brescia, F., Hochster, H., Cohn, A. A phase II study of milataxel: a novel taxane analogue in previously treated patients with advanced colorectal cancer. Cancer Chemother. Pharmacol. 61, 453-8. 
101. Ramnath, N., Schwartz, G. N., Smith, P., Bong, D., Kanter, P., Berdzik, J., Creaven, P. J., 2003. Phase I and pharmacokinetic study of anhydrovinblastine every 3 weeks in patients with refractory solid tumours. Cancer Chemother. Pharmacol. 51, 227 - 23.

102. Robert, F., Harper, K., Ackerman, J., Gupta, S., 2010. A phase I study of larotaxel (XRP9881) administered in combination with carboplatin in chemotherapy-naïve patients with stage IIIB or stage IV non-small cell lung cancer. Cancer Chemother. Pharmacol. 65, 227-34.

103. Saif, M.W., Sarantopoulos, J., Patnaik, A., Tolcher, A.W., Takimoto, C., Beeram, M., 2011. Tesetaxel, a new oral taxane, in combination with capecitabine: a phase I, doseescalation study in patients with advanced solid tumours. Cancer Chemother. Pharmacol. 68, 1565-73.

104. Sargent, J.M., Elgie, A.W., Williamson, C.J., Hill, B.T., 2003. Ex vivo effects of the dual topoisomerase inhibitor tafluposide (F 11782) on cells isolated from fresh tumor samples taken from patients with cancer. Anticancer Drug. 14, 467-73.

105. Saxe, T.G., 1987. Toxicity of medicinal herbal preparation. Am. Fam. Physician. 35, 135-142.

106. Scott, L., Soepenberg, O., Verweij, J., de Jonge, M.J., Th Planting, A.S., McGovern, D., Principe, P., Obach, R., Twelves, C., 2007. A multicentre phase I and pharmacokinetic study of BN80915 (diflomotecan) administered daily as a 20-min intravenous infusion for 5 days every 3 weeks to patients with advanced solid tumours. Ann. Oncol. 18, 56975.

107. Kapoor, S., 2012. Emerging role of berbamine as an anti-cancer agent in systemic malignancies besides chronic myeloid leukemia. J. Zhejiang Univ. Sci B. 13, 761-762.

108. Shengquan, L., Sze Ngong, H. L., 2013. Design of low-molecular-weight prodrugs for targeted delivery of anticancer agents. Pharmaceut. Anal. Acta. 4, 2; http://www.omicsonline.org/2153-2435/2153-2435-S1.12-013.pdf (abstract, 3rd International Conference and Exhibition on Pharmaceutics \& Novel Drug Delivery Systems, April 08-10, 2013 Hilton Chicago/Northbrook, USA)

109. Simoens, C., Vermorken, J.B., Korst, A.E., Pauwels, B., De Pooter, C.M., Pattyn, G.G., Lambrechts, H.A., Breillout, F., Lardon, F., 2006. Cell cycle effects of vinflunine, the most recent promising vinca alkaloid and its interaction with radiation, in vitro. Cancer Chemother. Pharmacol. 58, 210-218. 
110. Simon, M., Frank, A., Pierra, R., Susan, H., David, B., Michael, M., Arun, D., 2012. Cytotoxic effects of the novel isoflavone, phenoxodiol, on prostate cancer cell lines. J. Biosci. 37, 73-84.

111. Singer, J. W., Shaffer, S., Baker, B., Bernareggi, A., Stromatt, S., Nienstedt, D., Besman, M., 2005. Paclitaxel poliglumex (XYOTAX; CT-2103): an intracellularly targeted taxane. Anti-cancer Drug. 16, 243-54.

112. Slovackova, J., Smarda, J., Smardova, J., 2012. Roscovitine-induced apoptosis of H1299 cells depends on functional status of p53. Neoplasma 59, 606-12.

113. Smith, G.A., 1995. Current status of vinorelbine for breast cancer. Oncology 9, 767-73.

114. Sporn, M.B., Liby, K.T., 2005. Cancer chemoprevention: scientific promise, clinical uncertainty. Nat. Clin. Pract. Oncol. 2, 518-525.

115. Srivastava, V.N., Kumar, A.S., Gupta, J.K., Khanuja, M. M., 2005. Plant-based anticancer molecules: a chemical and biological profile of some important leads. Bioorg. Med. Chem. 13, 5892-908.

116. Stewart, D.C., Fred, B O., Jack, W S., 2006. Biological and clinical characterization of paclitaxel poliglumex (PPX, CT-2103), a macromolecular polymer-drug conjugate. Int. J. Nanomedicine. 1, 375-383.

117. Trocóniz, I.F., Cendrós, J.M., Soto, E., Pruñonosa, J., Perez-Mayoral, A., Peraire, C., Principe, P., Delavault, P., Cvitkovic, F., Lesimple, T., Obach, R., 2012. Population pharmacokinetic/pharmacodynamic modeling of drug-induced adverse effects of a novel homocamptothecin analog, elomotecan (BN80927), in a Phase I dose finding study in patients with advanced solid tumors. Cancer Chemother. Pharmacol. 70, 23950.

118. Tzakos, A.G., Kontogianni, V.G., Tsoumani, M., Kyriakou, E., Hwa, J., 2012. Rodrigues FA, Tselepis AD: Exploration of the antiplatelet activity profile of betulinic acid on human platelets. J Agric. Food Chem. 60, 6977-6983.

119. Verma, A. K., Singh, R. R., 2010. Induced Dwarf Mutant in Catharanthus roseus with Enhanced Antibacterial Activity. Indian J. Pharm. Sci. 72, 655-657.

120. Vey, N., Kantarjian, H., Tran, H., Beran, M., O'Brien, S., Bivins, C., Giles, F., Cortes, J., Cheson, B., Arbuck, S., Estey, E., 1999. Phase I and pharmacologic study of 9aminocamptothecin colloidal dispersion formulation in patients with refractory or relapsed acute leukemia. Ann. Oncol. 10, 577-83.

121. Wetzler, M., Segal, D., 2011. Omacetaxine as an Anticancer Therapeutic: What is Old is New Again. Curr. Pharma. Design. 17, 59-64. 
122. Wilken, R., Mysore, S. V., Marilene, B W., Eri, S. S., 2011. Curcumin: A review of anti-cancer properties and therapeutic activity in head and neck squamous cell carcinoma. Mol. Cancer 10, 12.

123. Willmann, M., Wacheck, V., Buckley, J., Nagy, K., Thalhammer, J., Paschke, R., Triche, T., Jansen, B., Selzer, E., 2009. Eur. J. Clin. Invest. 39, 384-94.

124. Wilson, L.B., 1975. Action of drugs on Microtubules. Life Sci. 12, 303-310.

125. Zhan, Y.P., Hyang, X.E., Cao, J., Lu, Y.Y., Wu, X.Y., Liu, J., Xu, X., Xiang, J., Ye, L.H., 2012. Clinical Safety and Efficacy of Kanglaite (Coix Seed Oil) Injection Combined with Chemotherapy in Treating Patients with Gastric Cancer. Asian Pacific J. Cancer Prev. 13, 5319-5321.

126. Yogeeswari, P., Sriram, D., 2005. Betulinic acid and its derivatives: A review on their biological properties. Curr. Med. Chem. 12, 657-666.

127. Zhang, Y., Trissel, L., 1999. A. Physical and chemical stability of etoposide phosphate solutions. J. Am. Pharm. Assoc (Wash). 39, 146-50.

128. Zhu, A.X., Ready, N., Clark, J.W., Safran, H., Amato, A., Salem, N., Pace, S., He, X., Zvereva, N., Lynch, T.J., Ryan, D.P., Supko, J.G., 2009. Phase I and pharmacokinetic study of gimatecan given orally once a week for 3 of 4 weeks in patients with advanced solid tumors. Clin. Cancer Res. 15, 374-81. 


\section{Appendix A. Supplementary data}

Supplementary Fig. I._ Chemical structures of various plant based natural and semisynthetic anticancer natural products.

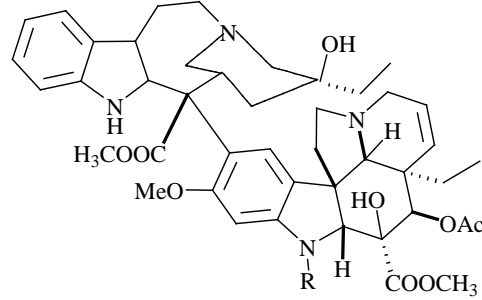

1. Vinblastine $\mathrm{R}=\mathrm{CH}_{3}$

2. Vincristine $\mathrm{R}=\mathrm{CHO}$

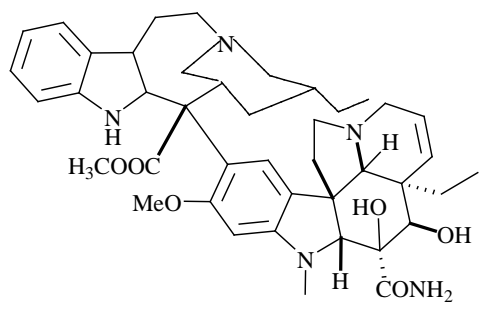

3.Vindesine

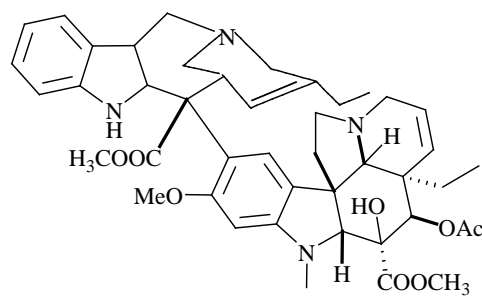

4.Navelbine
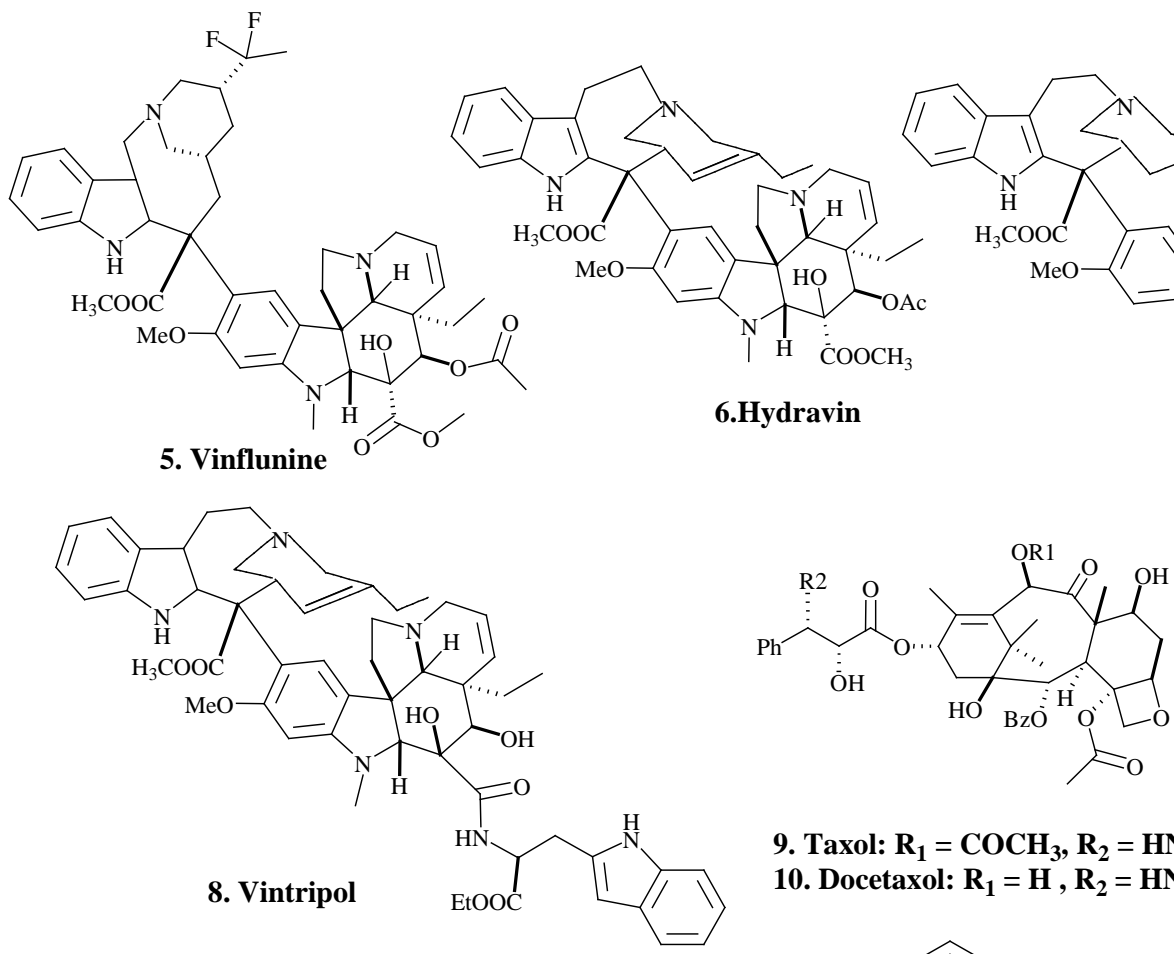

9. Taxol: $\mathbf{R}_{1}=\mathrm{COCH}_{3}, \mathbf{R}_{2}=\mathrm{HNCOC}_{6} \mathrm{H}_{5}$ 10. Docetaxol: $\mathrm{R}_{1}=\mathrm{H}, \mathrm{R}_{2}=\mathrm{HNCOOC}\left(\mathrm{CH}_{3}\right)_{3}$

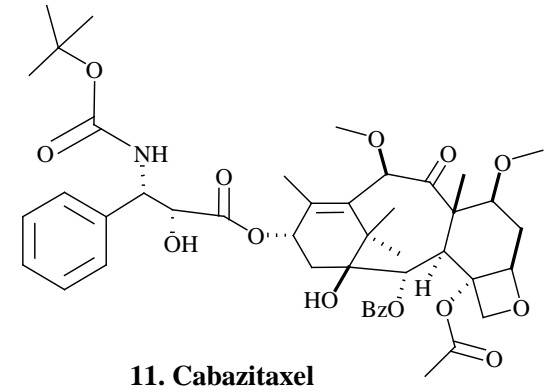



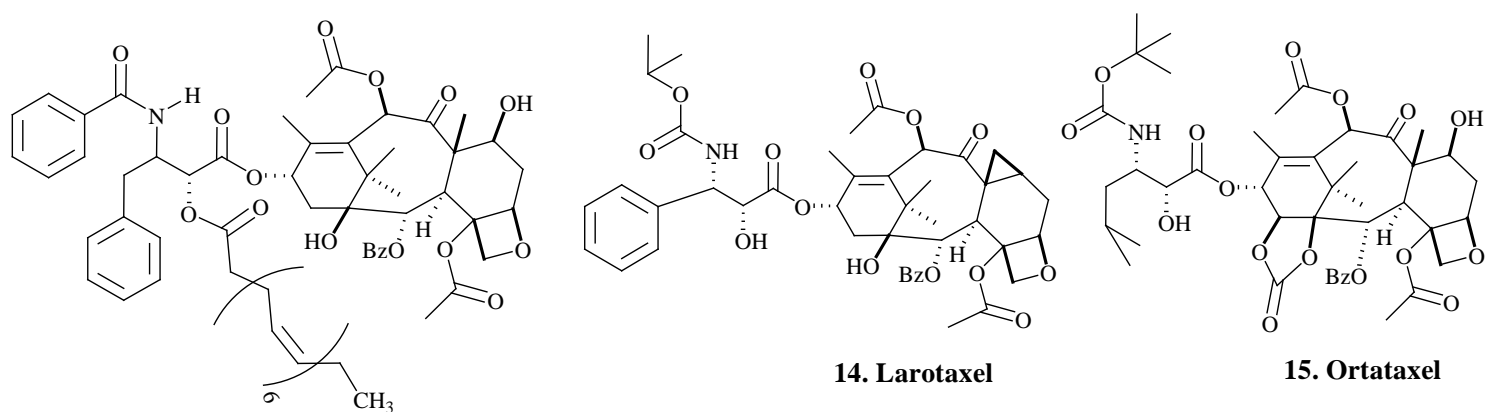

14. Larotaxel

15. Ortataxel

13. Taxoprexin
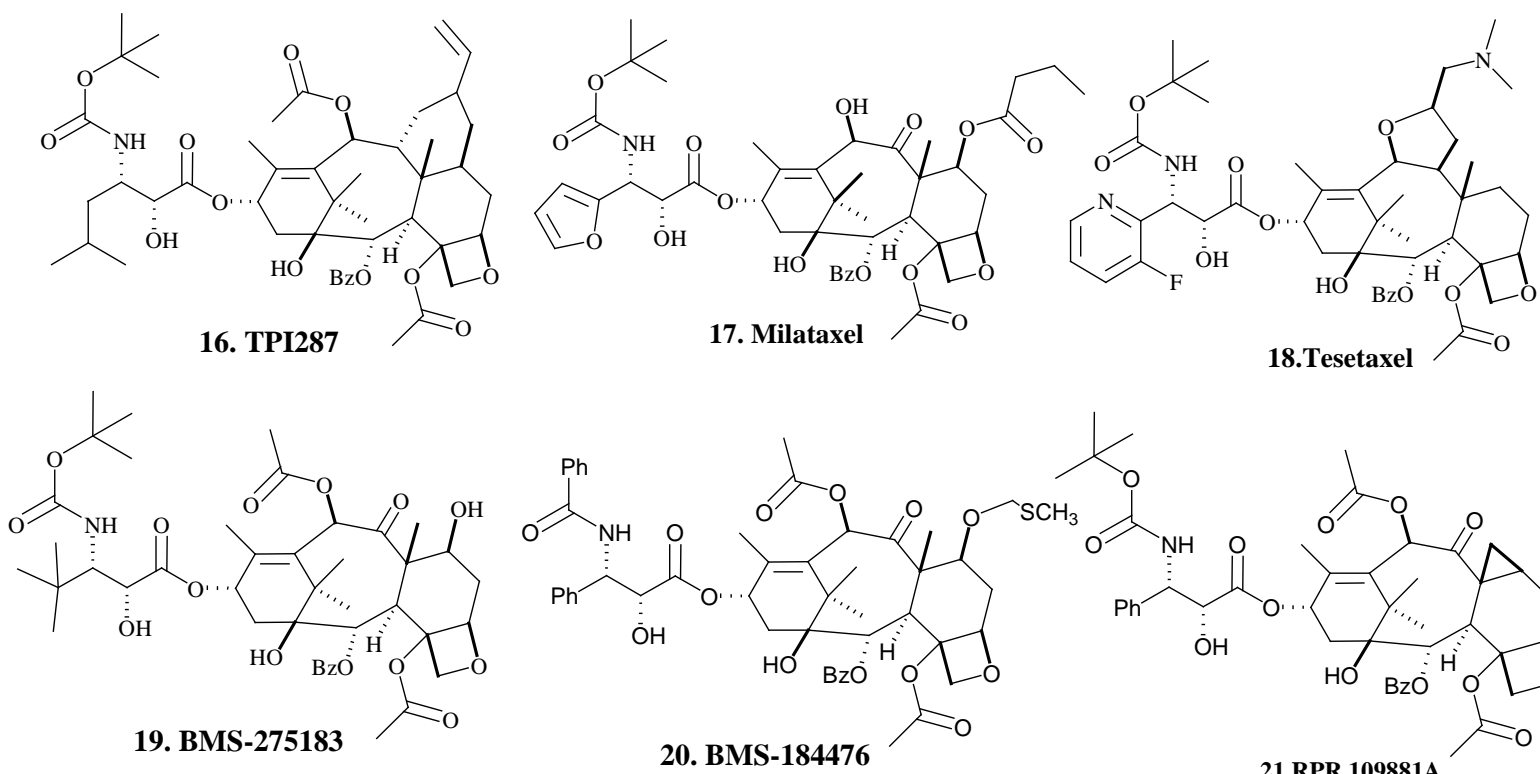

20. BMS-184476

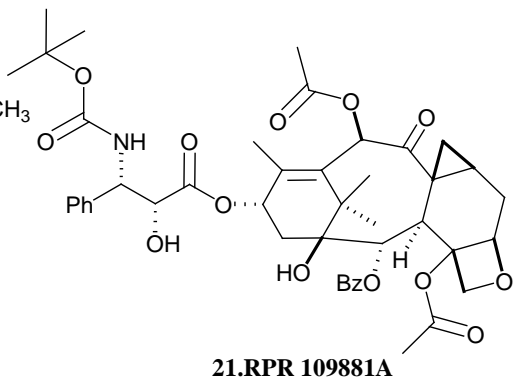

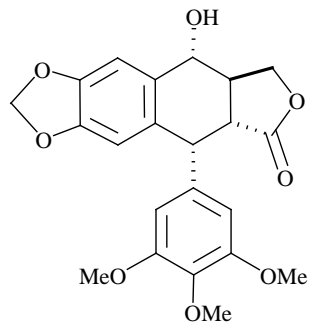

22. Podophyllotoxin

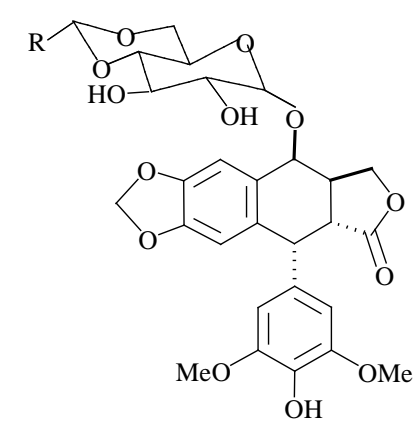

23. Etoposide $\mathbf{R}=\mathrm{CH}_{3}$

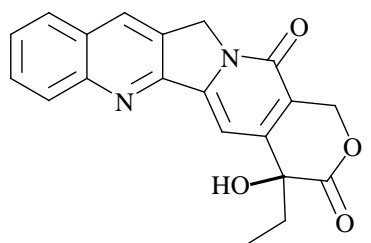

25. Camptothecin

24. Teniposide $\mathbf{R}=$<smiles>Cc1cccs1</smiles> 
<smiles>CCC1(O)C(=O)OCc2c1cc1n(c2=O)Cc2cc3c(CN(C)C)c(O)ccc3nc2-1</smiles><smiles>CCC1(O)C(=O)OCc2c1cc1n(c2=O)Cc2cc3c(N)cccc3nc2-1</smiles>

29. 9-amino camptothecin<smiles>CCC1(O)C(=O)OCc2c1cc1n(c2=O)Cc2c-1nc1cc(Cl)c(C)cc1c2CN1CCC(C)CC1</smiles><smiles>CCc1c2c(nc3ccc(OC(=O)N4CCC(N5CCCCC5)CC4)cc13)-c1cc3c(c(=O)n1C2)COC(=O)C3(O)CC</smiles>

27. Irinotecan<smiles>CCC1(O)C(=O)OCc2c1cc1n(c2=O)CCc2c-1nc1ccccc1c2CCNC(C)C</smiles><smiles>CCC1(O)CC(=O)OCc2c1cc1n(c2=O)Cc2cc3cc(F)c(F)cc3nc2-1</smiles>

31. Diflomotecan<smiles>[R]c1c2c(nc3ccccc13)-c1cc3c(c(=O)n1C2)COC(=O)C3(O)CC</smiles>

30. Karenitecin

32. Gimatecan
$\mathrm{R}={ }_{\mathrm{Si}}-$ $\mathrm{n}=K \mathrm{~N}_{-\mathrm{O}}<$

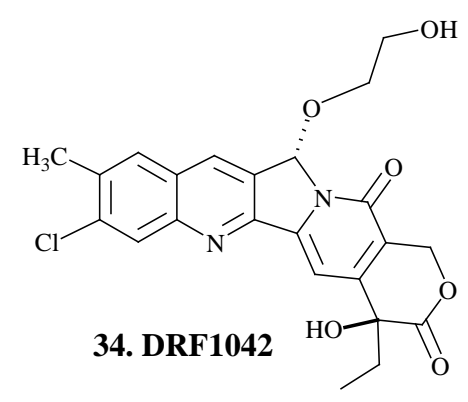<smiles>CCC1(O)CC(=O)OCc2c1cc1n(c2=O)Cc2c-1nc1cc(F)c(C)c3c1c2[C@@H](N)CC3</smiles>

35. Exatecan mesylate<smiles>CCC1(O)C(=O)OCc2c1cc1n(c2=O)Cc2cc3c([N+](=O)[O-])cccc3nc2-1</smiles>

36. Rubitecan<smiles>CCC(=O)OC1(CC)C(=O)OCc2c1cc1n(c2=O)Cc2cc3ccccc3nc2-1</smiles>

37.CZ-48

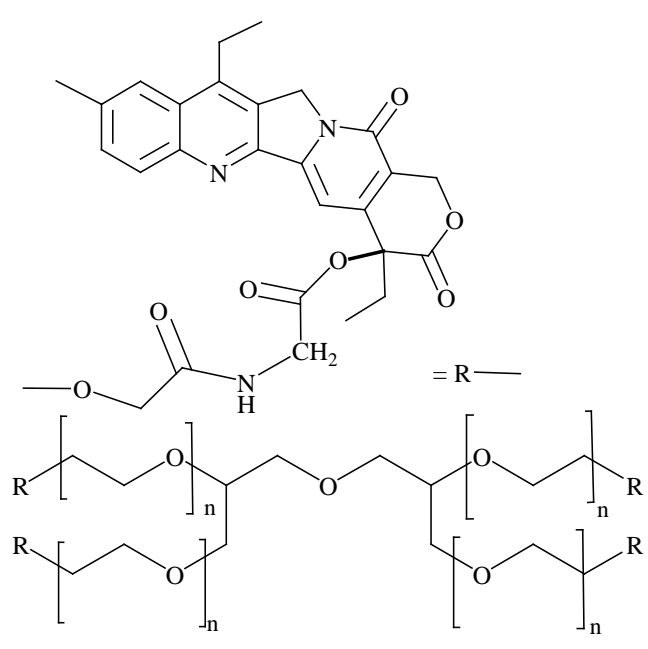

39. EZN-2208 


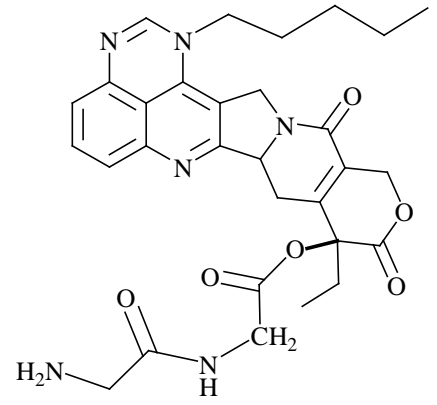

38.TP-300

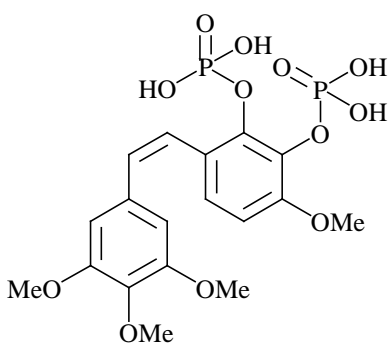

42. CA-1P<smiles>CN1CCC(c2c(O)cc(O)c3c2CC(c2ccccc2Cl)=CC3=O)C(O)C1</smiles>

46. Rohitukine<smiles>COc1ccc(/C=C\c2cc(OC)c(OC)c(OC)c2)cc1O</smiles>

40. Combrastatin A4<smiles>COC(=O)C[C@@](O)(CCCC(C)(C)O)C(=O)O[C@H]1C(OC)=CC23CCCN2CCc2cc4c(cc2[C@@H]13)OCO4</smiles>

43. Homoharringtonine<smiles>COc1cc(/C=C/C(=O)CC(=O)/C=C/c2ccc(O)c(OC)c2)ccc1O</smiles>

47. Curcumin<smiles>COc1ccc(/C=C\c2cc(OC)c(OC)c(OC)c2)cc1OP(=O)(O)O</smiles>

41. CA-4P

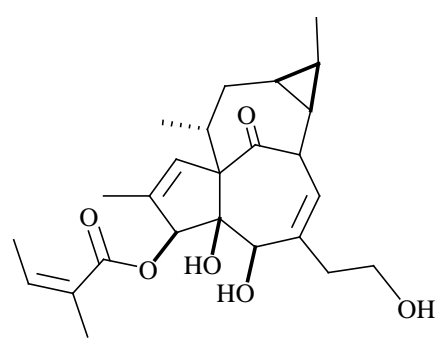

44. Ingenol-3-O-angelate

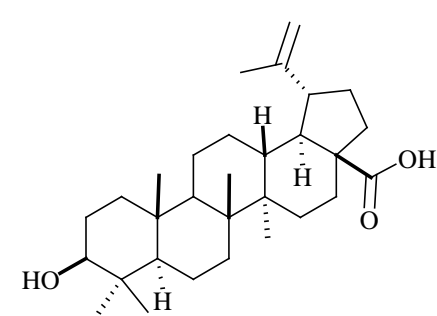

45. Betulinic acid 